\title{
Biogas Production using Sugarcane Bagasse
}

\section{Edward Kwaku Armah $^{1^{*}}$, Bright Boafo Boamah ${ }^{2}$, Emmanuel Kweinor Tetteh $^{1}$ \& Gifty OppongBoakye ${ }^{3}$}

${ }^{1}$ Department of Chemical Engineering, Durban University of Technology, Durban, South Africa.

${ }^{2}$ Department of Pharmacology, Kwame Nkrumah University of Science and Technology, Kumasi, Ghana.

${ }^{3}$ Department of Mechanical Engineering, University of Leeds, Leeds, United Kingdom

Emails: ${ }^{1 *}$ edwardkarmah@gmail.com; ${ }^{2}$ briteboafo@gmail.com;

1ektetteh34@gmail.com; ${ }^{3}$ giftyoppong57@gmail.com

\section{ABSTRACT}

Non-renewable energy sources have been found to pose various environmental problems such as greenhouse gas emissions as they tend to deplete at faster rates. Renewable energy could, however, replace the conventional sources of energy such as fossil fuel and oil, serving as an alternative source of energy. Biological processes such as fermentation and anaerobic digestion for the past decades have given rise to the production of biofuels such as biogas and bioethanol. The inchoate gain in the shift for a renewable source of energy is that the feedstock is often a by-product, a residue or waste product of other processes without the competition of arable land. One of such feedstock is sugarcane bagasse. Biochemical methane potential (BMP) test is generally used to determine the possible methane that can be obtained from feedstocks. This study, however,aims at optimizing the anaerobic digestion of sugarcane bagasse with cow dungin a BMP test and controlled at mesophilic temperature $(35 \pm 2)$. Biodigester labelled as 1A (containing only the inoculum) was used as the control for the experiment, biodigester 2A (with 1:1 feedstock to inoculum ratio), biodigester 1C (without purification but a 1:3 feedstock to inoculum ratio) and biodigester 1D (with purification after a 1:3 feedstock to inoculum ratio) were reported in this study. Methane production was measured for a retention time (days) of 21 days using a 1000ml Schott bottles as biodigesters in batch mode. Sugarcanebagassewas characterized in the batch reactor to enable the inoculum activity and the biogas volume reported during the 21 days. The highest yield of methane was found to be $78 \%$ whiles the cumulative average biogas yield was 167 mlfor the 21 days. However, the use of chemical absorption techniques for carbon dioxide removal in anaerobic digestion for biogas production is recommended as a promising factor.

Keywords:Anaerobic digestion, Biogas, Feedstock, Sugarcane bagasse

\section{Corresponding Author:Edward Kwaku Armah}

\section{INTRODUCTION}

The increase in fuel prices, emission of greenhouse gases, and the over-reliance on nonrenewable energy has braved researchers in the past decades to find alternatives methods to obtain a sustainable form of energy. Urbanisation has also led to the rapid production of wastes leading to poor waste management practices in developing nations [1]. All these highlights the fact that renewable energy still remains a vital demand to cater for the ever-increasing energy consumption and the 
depletion of these fossil resources from non-renewable energy sources[2]. According to Gu, et al. [3], studies have been carried out to find renewable energy sources as fossil fuel replacement.

The synthesis of a renewable energy source as an alternative to non-renewable energy source has been evaluated where energy is produced from biogas through anaerobic digestion process [4]. Biogas consists mainly of $60-70 \%$ methane, $20-30 \%$ carbon dioxide and also the digestatewhich is also collected from the anaerobic digestion of organic materials as effluent $[5,6]$. The gas produced has been found for generating electricity and also in the production of combined heat and power using appropriate technologies making the process promising [7]. In anaerobic digestion (AD), the organic matter of the biomass is decomposed by the intensive reaction of a large range of microorganisms in the absence of oxygen [8]. Since it is carried out by these microorganisms and dependent on factors such as temperature, hydraulic retention time (HRT), carbon to nitrogen ratio, solid to water content, $\mathrm{pH}$, and the organic loading rate, the process is considered slow $[9,10]$. AD involves four main stages as a result of the biodegradation of organic matter by a consortium of microorganisms [11]. The first stage, hydrolysis, is the rate-determining step where carbohydrates, proteins, and fats present in the biomass converted to glucose, amino acids, and fatty acids respectively. Acidogenesis involves the conversion of these products to volatile fatty acids by acidogenic bacteria. The volatile acid products are then converted to carbon dioxide, hydrogen and acetates by acetogenic bacteria then finally the carbon dioxide produced can react with the hydrogen present to produce methane or the acetate breaks down to form methane and carbon dioxide with other trace compounds [12,13].

Comparatively, anaerobes have been found to be most active at mesophilic temperatures than thermophilic temperatures as the latter tend to require higher heat input and thus, this study focused on the former [14]. Limitations such as process instability, process failure, poor methane yield, and large retention time of 30-50 days have limited the full exploitation of the anaerobic digestion process [15]. Processes such as co-digestion, low organic loading to avoid over loading in biodigesters, pretreatment techniques to enhance cellulose and disrupt lignin, and the use of energy crops as feedstocks, have been found to increase the efficacy of biogas production through anaerobic digestion [9, 16, 17].

Sugarcane bagasse is a well-known biological residue which is widely generated from the sugar mill factories [18]. However, this residue is mostly used as fuel in low-efficiency cogeneration systems or even left to decay on the fields due to lack of incentives to produce bioenergy from them [19]. A biogas program was however launched in 2012 to stimulate and increase the sustainable use of biomass such as sugarcane bagasse for biogas production, including a future mandatory share of biomethane into the National gas grid in Sao Paulo, Brazil [20].

Thepresent study was carried out to determine the effect of sugarcane bagasse as a feedstock for biogas production in a biochemical methane potential test under mesophilic anaerobic digestion in a batch mode.

\section{MATERIALS AND METHODS}

The biochemical methane potential (BMP) test was carried out to determine the potential of the sugarcane bagasse(shown in Figure 1)with cow dungused as the inoculum.

\section{Material sampling and Chemicals used}

Sugarcane bagasse, a residue from sugarcane was obtained from Komenda; a town in the Central region of Ghana was used as the feedstock for the biogas production. The choice of feedstock was due to the bioavailability of the feedstock for use in energy generation. The fresh cow dung used as inoculum was obtained from a cattle farm in the same municipality to provide the necessary bacteria for the digestion process. Sodium hydroxide $(\mathrm{NaOH})$ was used to adjust the $\mathrm{pH}$ of the 
anaerobic digestion process to cater for volatile acids that may be generated to an optimum $\mathrm{pH}$ of 6.57.5 , required for the process.

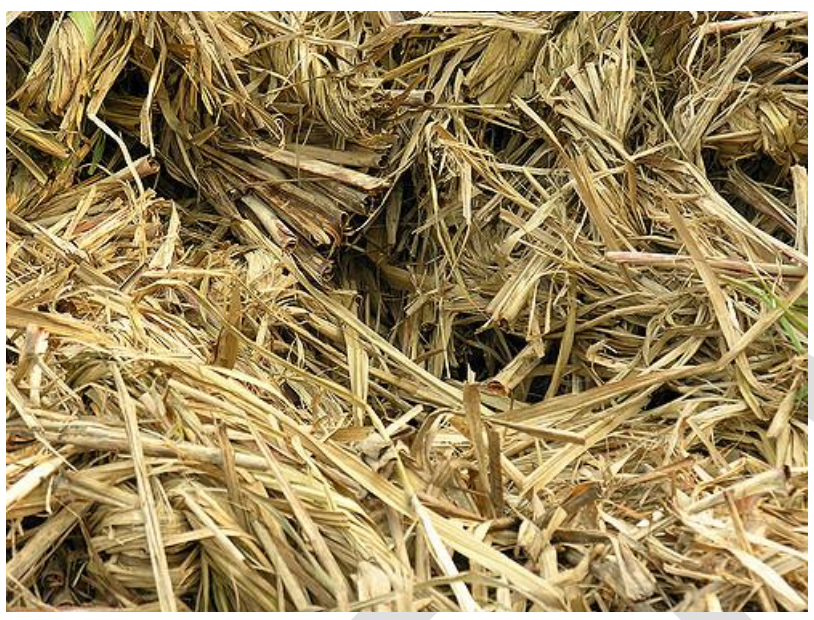

Fig 1: Harvested sugarcane bagasse

It has been observed from a study that volatile fatty acids production rate is much higher than the methane production rate and could result in $\mathrm{pH}$ levels below the optimum range, thereby inhibiting methanogens. This is attributed to the higher level of sensitivity to acidic conditions [11]. Deionized water was also used to prepare the solutions and cleaning the equipment. Nitrogen $\left(\mathrm{N}_{2}\right)$ gas was used to purge the entire system to create the anaerobic digestion environment. The inoculum was kept in a sealed schott bottles, stored at $4^{\circ} \mathrm{C}$ in a refrigerator until further chemical analysis.

Feeding rates of feedstocks and inoculum in each digester

Biodigesters were fed gradually according to Table 1 and kept in a circulating water bath operating at a mesophilic temperature of $35 \pm 1{ }^{\circ} \mathrm{C}$. Biogas production was measured for a retention period of 21 days by the water displacement technique.

Table 1. Experimental design for the feedstock and the Inoculum

\begin{tabular}{|c|c|c|}
\hline Biodigester ID & $\begin{array}{c}\text { Feedstock: Sugarcane } \\
\text { bagasse(\% RM) }\end{array}$ & Inoculum (cattle manure) \\
\hline 1A & 0 & 100 \\
\hline 1B & 50 & 50 \\
\hline 1C & 25 & 75 \\
\hline 1D & 25 & 75 \\
\hline
\end{tabular}

\section{Primary Characterization}

The feedstock (sugarcane bagasse) was washed and dried to remove the unwanted particles. Furthermore, it was shredded and milled to obtain a particle size of $10 \mathrm{~mm}$. This was done to increase the surface area during the anaerobic digestion process and to make the microorganisms accessible for degradation.

\section{Feedstock and Inoculum characterization}

The raw feedstock was characterized and analyzed for total solids, moisture content, volatile solids, and ash contents in accordance with the standard methods [21]. All procedures were carried out in the laboratory using a precision balance for weighing the mass, a convection oven for drying 
feedstock and inoculum and a muffle furnace for the ashing process. The weight loss could be determineddirectly by oven drying in an oven regulated at $105^{\circ} \mathrm{C}$ to a constant weight.

\section{Experimental setup and procedure}

The total solids and volatile solids of the feedstocks and inoculum were pre-determined and used to prepare the digestion samples into the $1000 \mathrm{ml}$ Schott bottles (used as the biodigesters) with an effective volume of $800-\mathrm{ml}$. For each run, a headspace of $200 \mathrm{ml}$ was left which was purged with $\mathrm{N}_{2}$ to create the anaerobic environment within the biodigesters as shown in Figure 2. The biodigesters were closed air-tight with rubber caps and incubated in a circulating water bath. Since it is a batch system, it was made to run until anaerobic digestion was complete. Stirring was carried out periodically by cautiously shaking each biodigester to ensure uniformity. The composition of biogas was analyzed from the BMP test using a gas chromatograph (SRI $8610 \mathrm{GC}$ ) equipped with thermal conductivity detector, packed with 6' Hayesep-D/6' Molecular Sieve-13 X.

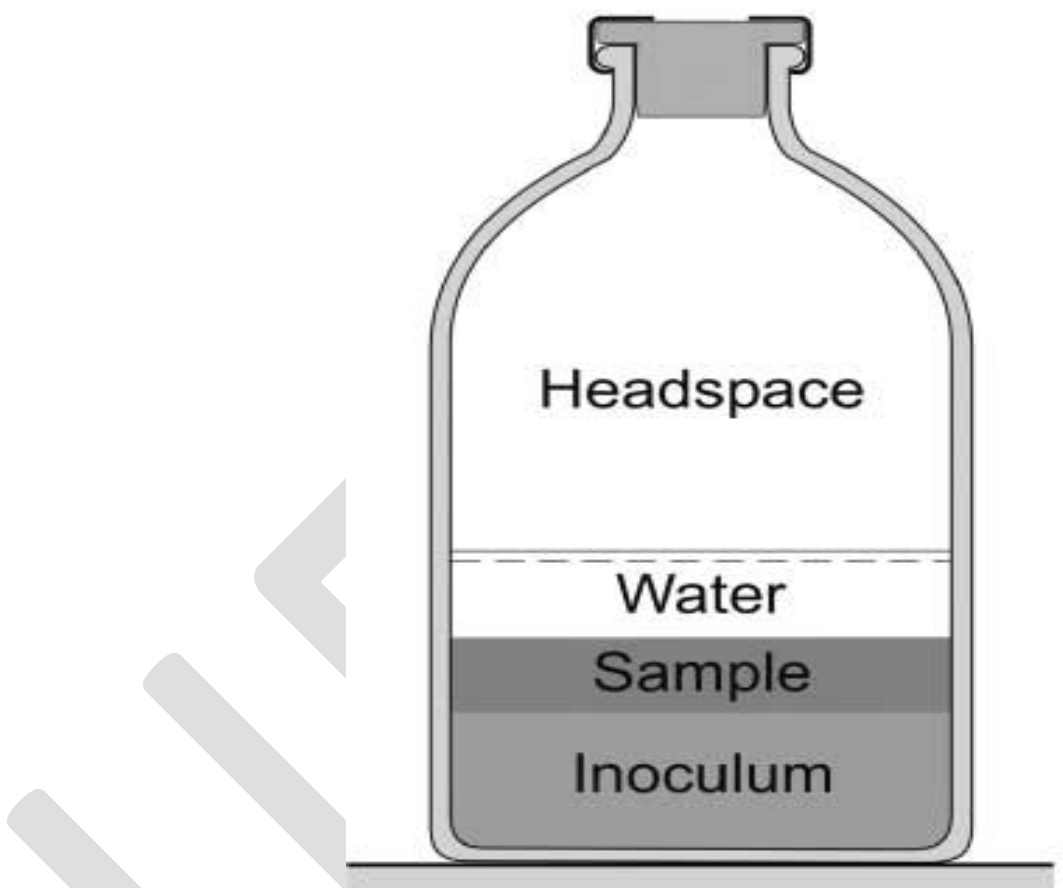

Fig 2: Schematic of the Biochemical methane potential test with loading of inoculum and feedstock for each biodigester

The anaerobic digestion system was designed to quantitatively determine the volume of biogas produced using a water displacement technique, and qualitatively for methane $\left(\mathrm{CH}_{4}\right)$ and carbon dioxide $\left(\mathrm{CO}_{2}\right)$. After feeding the biodigesters at an optimal loading rate as in Table 1, it was observed that the $\mathrm{pH}$ in each biodigester was within the same range as reported in a study by Simo et al., [18] and by Maile, et al. [22]though $\mathrm{CaCO}_{3}$ and $\mathrm{NaOH}$ wereused by the later to control the alkalinity during the anaerobic digestion. Biodigester mode of loading is shown in fig 2.

\section{RESULTS AND DISCUSSION}

The biogas yield of sugarcane bagasse was obtained through BMP assays under mesophilic temperature for a 21 day period for each four, $1000 \mathrm{ml}$ biodigesters labelled $1 \mathrm{~A}, 1 \mathrm{~B}, 1 \mathrm{C}$ and $1 \mathrm{D}$. The results of the BMP assays are presented in Figures 3-7.

Sodium hydroxide reacts with carbon dioxide according to the following chemical reactions[23]: 


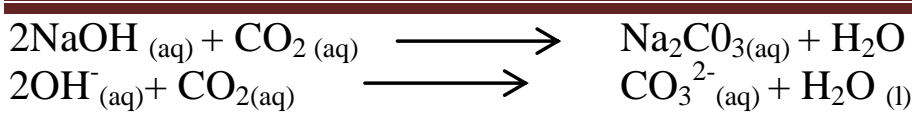

The effect of the absorption of carbon dioxide in this $\mathrm{pH}$ of each biodigester was kept within the optimum working range of 6.5-7.5 as $\mathrm{NaOH}$ was used to control the alkalinity of the anaerobic digestion process.

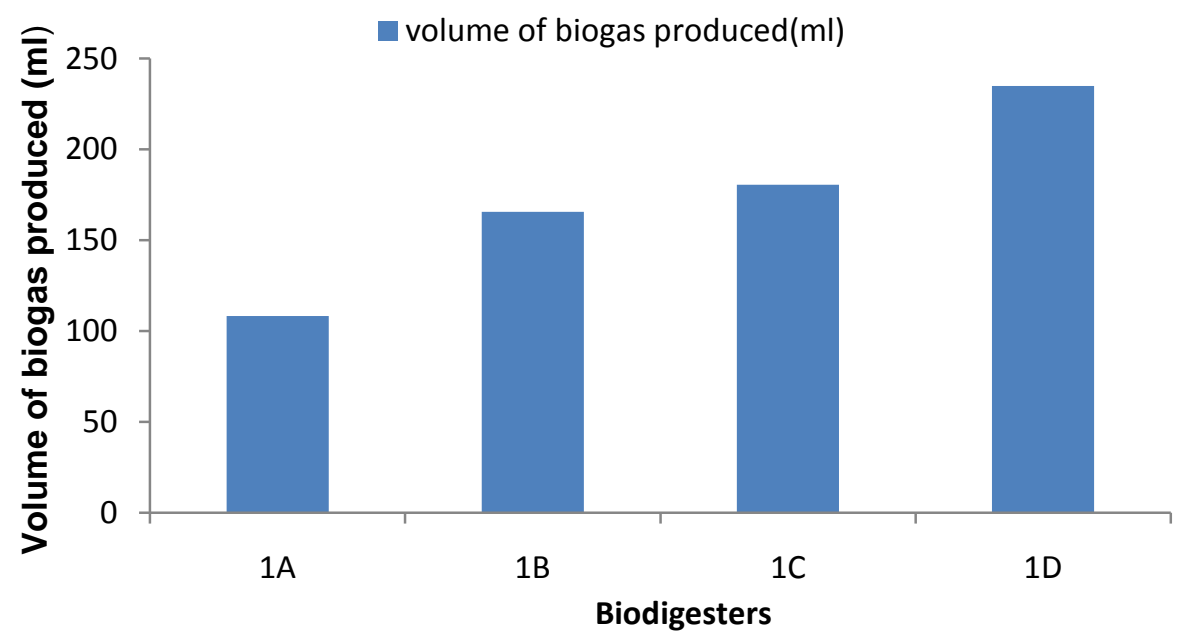

Fig 3: Cumulative biogas yield per each biodigester for the 21 days.

$\mathrm{NaOHhas}$ an effect on the composition of carbon dioxide during anaerobic digestion to produce biogas. The result in fig. 3 shows that biodigester 1D obtained the highest volume of biogas $(235 \mathrm{ml})$ from a 1:3 feedstock to inoculum ratio using the downward displacement after chemical absorption of $\mathrm{CO}_{2}$ with $\mathrm{NaOH}$. It was followed by biodigester $1 \mathrm{C}(181 \mathrm{ml})$, where the feedstock to inoculum ratio wassame as biodigester 1D at 1:3 but without any chemical absorption of carbon dioxide. Biodigester 1A gave the lowest yield of biogas $(108 \mathrm{ml})$ as this was due to the fact that no feedstock was available for biodegradation by the microorganisms that could also contribute to the enhancement of the yield of biogas during the anaerobic digestion. $\mathrm{CO}_{2}$ removal was thus absent in this biodigester $(1 \mathrm{~A})$. Hence, the micorganisms within the biodigester $1 \mathrm{~A}$ produced only the amount of biogas they could produce by itself without feedstock biodegradation. Nonetheless, the quality of the biogas increased as more carbon dioxide is removed from the biogas. In a similar study, biodigesters that had no inoculum stoppped producing ealier than the other biodigesters that had inoculum [7]. This was attributed to the accumulation of volatile fatty acids that might have been generated during the anaerobic digestion process. In this experiment, all the biodigesters had inoculum present, digestion was complete for all the biodigesters and hence this finding was in contrast to what was reported in a study by Maile et al., [7]. 


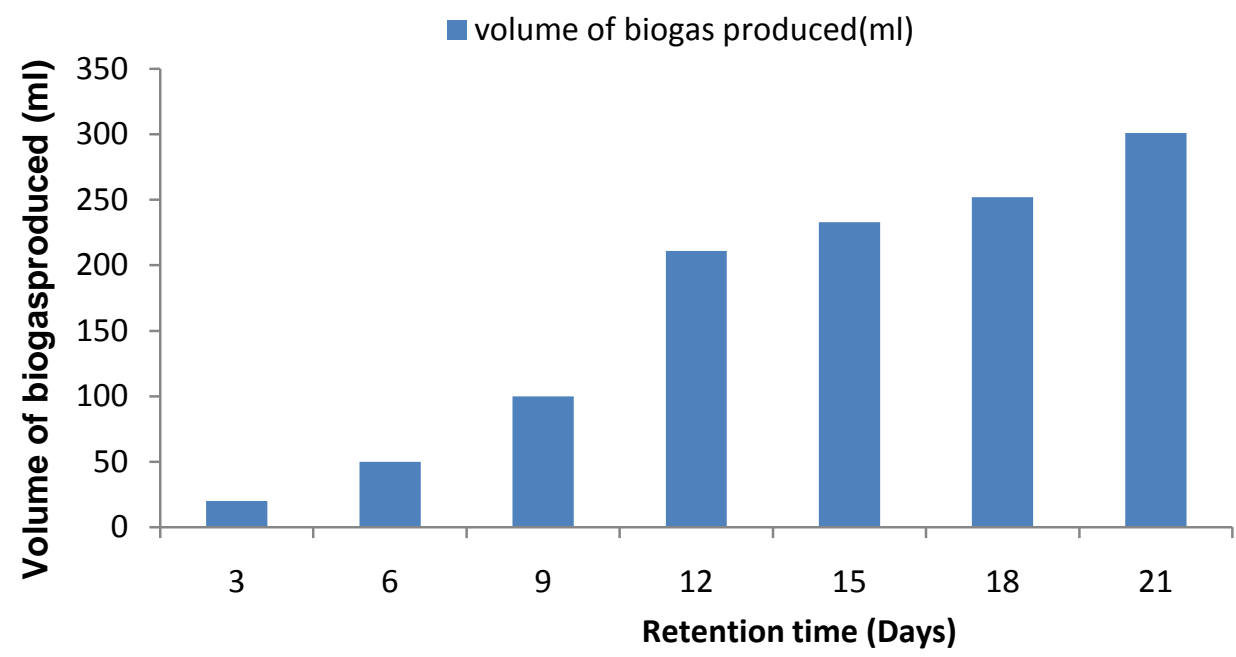

Fig 4: Cumulative biogas production ( $\mathrm{ml}$ ) versus the retention time (days)

Biogas production was relatively slow at the beginning of the experiment as shown in fig. 4 and was observed to commence on day 3 and increased up to day 21 after which the digestion process seized. This was due to the lag phase of the microorganisms within each biodigester which plays a significant role in the biogas production under anaerobic digestion. During anaerobic digestion, microorganisms have been found to acclimatize within biodigesters before the digestion period begins. In this study, the lag phase was found to last for 2 days. The lag phase of microorganisms has been found to decrease under pretreatments using ionic liquids[24]. Biogas production from biodigesters with feedstocks pretreated with ionic liquids was found to commence within a very short period of time.

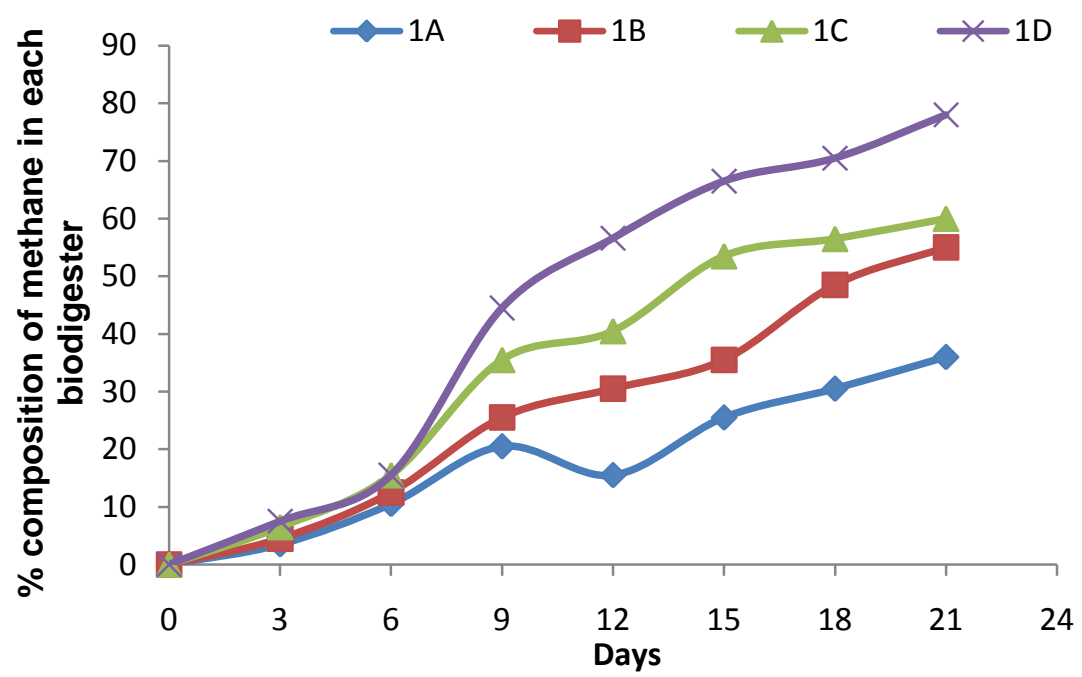

Fig 5: Percentage composition of methane in each biodigester against the retention time (days) 
The hydraulic retention time for mesophilic digesters ranges from 15 to 30 days and 12 to 14 days for thermophilic digesters [25]. However, the hydraulic retention time in this study was similar to what was reported by [23] as represented in fig. 5. It has been found in a study that when the methane content falls to as little as 50\%, biogas is no longer combustible[26] as observed in biodigester 1A.The hydraulic retention time in this study was found to be similar to what was reported by Simo et.al [18], a retention time for which most anaerobic digesters run. It can be observed from fig 5 . that biodigester 1A achieved the lowest methane yield after the 21 days of anaerobic digestion $\left(36 \% \mathrm{CH}_{4}\right)$ whiles biodigester $1 \mathrm{D}$ achieved the highest yield $\left(78 \% \mathrm{CH}_{4}\right)$ of biogas.

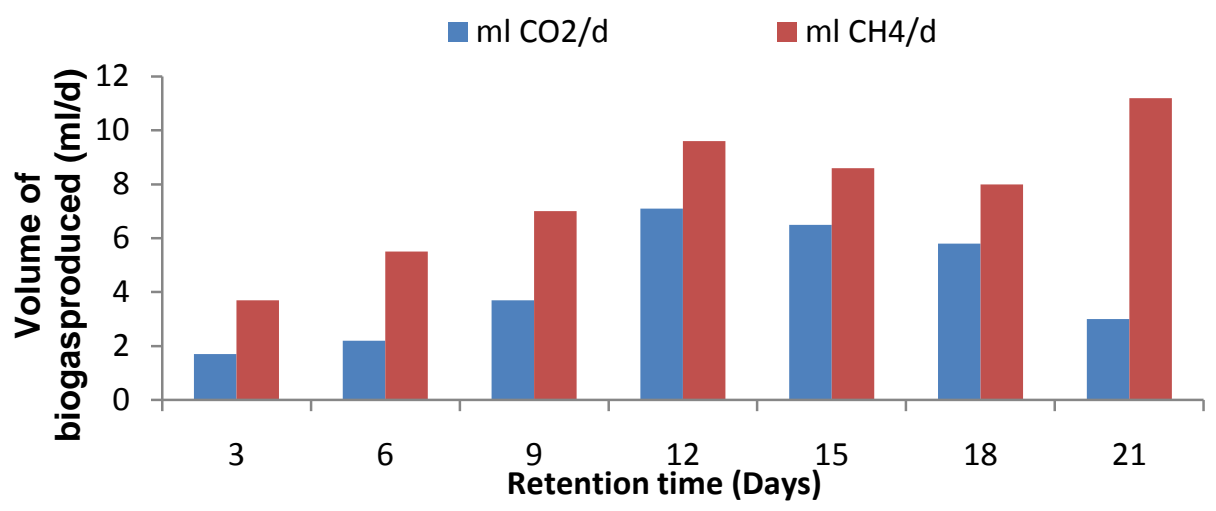

Fig 6. Cumulative biogas yield (ml/d) versus retention time for $\mathrm{CH}_{4}$ and $\mathrm{CO}_{2}$

Fig. 6 depicts the yield of biogas for each 3 days interval until the anaerobic digestion process was complete. The result also shows an increase in biogas production during the first 12 days of the experiment and was observed to decrease from day 14 to day 20 after which it rose sharply on day 21 and finally dropped.This high rate on the first 12 days was due to maximal hydrolytic activity of the ferment which in turn caused a rapid carbon dioxide production, hence it is necessary to remove the $\mathrm{CO}_{2}$ generated as in the case of biodigester 1D.

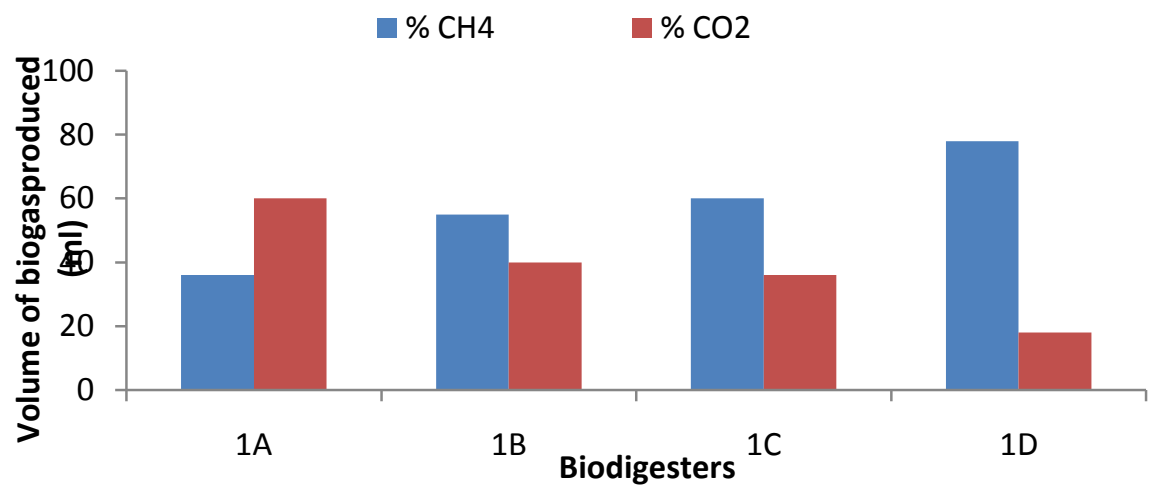

Fig 7. Comparison of the biogas yield with respect to $\mathrm{CH}_{4}$ and $\mathrm{CO}_{2}$ in each biodigester

$\mathrm{CO}_{2}$ removalwas found in this study to be capable of producing high methane content. Biodigester $1 \mathrm{~A}$ contained only the inoculum without the feedstock and was used as the control for the experiment, biodigester 1B contained both the inoculum together with the feedstock in a 1:1 ratio and biodigester 
1C contained a 1:3 ratio of feedstock to inoculum. Biodigester 1D was fed with the same loading rate just as biodigester $1 \mathrm{C}$ but was made to run over $3 \mathrm{M} \mathrm{NaOH}$ for carbon dioxide removal. Thus biodigester 1D reported the highest methane composition of $78 \%$ with the use of $3 \mathrm{M} \mathrm{NaOH}$ for $\mathrm{CO}_{2}$ purification which is similar to what was reported by Maile et al., [23]. Also, the $\mathrm{CO}_{2}$ yield was found to decrease as the yield of $\mathrm{CH}_{4}$ increased and thus the removal efficiency was observed to be significant in this study. Acetates, carbon dioxide and hydrogen molecules are converted by methanogenic bacteria to methane and thus, a good control in the removal of $\mathrm{CO}_{2}$ has been found in this study to enhance the methane yield thereby removing $\mathrm{CO}_{2}$ concentrations using stronger alkalis like $\mathrm{NaOH}$.

\section{CONCLUSION}

Biogas production from sugarcane bagasse with cow dung was studied to determine the biochemical methane potential at laboratory scale in a batch mode. Despite sugarcane bagasse considered as one of the most abundant wastes generated from the sugar mill industry, it also institutes a good potential for bioenergy productionsuch as biogas.Based on the results of the study, biodigesters with 1:3 feedstocks to inoculum ratio followed by $\mathrm{CO}_{2}$ purification obtained the highest yield of biogas. Biodigester 1A obtained the lowest yield where the inoculum was made to produce the biogas without any feedstock. The highest methane composition was found to be $78 \%$ of the total yield of biogas produced.The cumulative average biogas yield was $167 \mathrm{mlfor}$ the 21 days of anaerobic digestion. Biogas production after purification for carbon dioxide absorption is however considered promising as it achieved the highest yield.pH has been found in this study to play avital role in the anaerobic digestion process and thus the optimum range should be maintained throughout the process due to volatile acids produced during the acidogenesis stage. This prevents overloading of feedstocks for bacteria degradation and ensures successful completion of the biogas production.Other factors such as temperature and the organic loading rate are also key parameters that influence the anaerobic digestion process. Therefore, sugarcane bagasse has the potential to produce biomethane which can be used to ease the dependency on fossil fuel derived energy and as an alternative energy source for combined heat and energy which is eco-friendly. Anaerobic digestion at mesophilic temperatures was found to be a viable process whereas processes such as inhibitor control during anaerobic digestion and cost-effective pretreatment are warranted to all researchers.

\section{ACKNOWLEDGEMENT}

The authors are thankful to the Kwame Nkrumah University of Science and Technology, Kumasifor the use of their laboratory facilities during the research findings.

\section{DECLARATION OF INTEREST}

The authors declare that this article content has no conflict of interest.

\section{REFERENCES}

[1] N. Tawoma, "Valorisation of biowaste via production of biogas and Biofertilizer," Master of Science in Engineering, Discipline of Chemical Engineering, University of Kwazulu Natal, 2015.

[2] A. Sørensen, M. Lübeck, P. S. Lübeck, and B. K. Ahring, "Fungal beta-glucosidases: a bottleneck in industrial use of lignocellulosic materials," Biomolecules, vol. 3, pp. 612-631, 2013.

[3] H. Gu, K. Zhang, Y. Wang, Y. Huang, N. Hewitt, and A. P. Roskilly, "Waste biomass from production process co-firing with coal in a steam boiler to reduce fossil fuel consumption: A case study," Journal of Energy Chemistry, vol. 22, pp. 413-419, 2013. 
DOI : https://dx.doi.org/10.26808/rs.ed.i7v6.17

International Journal of Emerging Trends in Engineering and Developmen

Issue 7,Vol.6 (October-November 2017)

Available online on http://www.rspublication.com/ijeted/ijeted_index.htm

ISSN 2249-6149

[4] H. M. El-Mashad and R. Zhang, "Biogas production from co-digestion of dairy manure and food waste," Bioresource technology, vol. 101, pp. 4021-4028, 2010.

[5] M. Biarnes. (2017). Biomass to Biogas-Anaerobic Digestion. Available: http://www.einst.com/biomass-to-biogas/

[6] T. Abbasi, S. Tauseef, and S. Abbasi, "Anaerobic digestion for global warming control and energy generation-an overview," Renewable and Sustainable Energy Reviews, vol. 16, pp. 3228-3242, 2012.

[7] I. Maile, E. Muzenda, and C. Mbohwa, "Biochemical methane potential of OFMSW for City of Johannesburg," 2016.

[8] L. N. Liew, J. Shi, and Y. Li, "Methane production from solid-state anaerobic digestion of lignocellulosic biomass," Biomass and Bioenergy, vol. 46, pp. 125-132, 2012.

[9] F. R. Ribeiro, F. Passos, L. V. A. Gurgel, B. E. L. Baêta, and S. F. de Aquino, "Anaerobic digestion of hemicellulose hydrolysate produced after hydrothermal pretreatment of sugarcane bagasse in UASB reactor," Science of the Total Environment, vol. 584, pp. 1108-1113, 2017.

[10] O. Maile, H. Tesfagiorgis, and E. Muzenda, "Factors Influencing Chemical Absorption of CO 2 and H $2 \mathrm{~S}$ in Biogas Purification: A Review," in World Congress on Engineering and Computer Science, San Francisco, USA, 2015.

[11] S. K. Khanal, Anaerobic biotechnology for bioenergy production: principles and applications: John Wiley \& Sons, 2011.

[12] N. M. C. Saady and D. I. Massé, "Impact of organic loading rate on psychrophilic anaerobic digestion of solid dairy manure," Energies, vol. 8, pp. 1990-2007, 2015.

[13] Y. Sun and J. Cheng, "Hydrolysis of lignocellulosic materials for ethanol production: a review," Bioresource technology, vol. 83, pp. 1-11, 2002.

[14] K. Mital, Biogas systems: policies, progress and prospects: Taylor \& Francis, 1997.

[15] I. A. Nges, "Anaerobic digestion of crop and waste biomass: Impact of feedstock characteristics on process performance," Doctoral, Luund University (Media-Tryck), 2012.

[16] P. Alvira, E. Tomás-Pejó, M. Ballesteros, and M. Negro, "Pretreatment technologies for an efficient bioethanol production process based on enzymatic hydrolysis: a review," Bioresource technology, vol. 101, pp. 4851-4861, 2010.

[17] C. Eliyan, "Anaerobic digestion of municipal solid waste in thermophilic continuous operation," Master of Science, School of Environment, Resource and Development, Asian School of Technology, 2007.

[18] W. S. F. Simo, N. E. Jong, and C. Kapseu, "Improving Biogas Production of Sugarcane Bagasse by Hydrothermal Pretreatment," Chemical and Biomolecular Engineering, vol. 1, pp. 21-25, 2016.

[19] M. R. L. Leal, M. V. Galdos, F. V. Scarpare, J. E. Seabra, A. Walter, and C. O. Oliveira, "Sugarcane straw availability, quality, recovery and energy use: a literature review," Biomass and Bioenergy, vol. 53, pp. 11-19, 2013.

[20] L. Janke, A. Leite, M. Nikolausz, T. Schmidt, J. Liebetrau, M. Nelles, et al., "Biogas production from sugarcane waste: assessment on kinetic challenges for process designing," International journal of molecular sciences, vol. 16, pp. 20685-20703, 2015.

[21] A. Sluiter, B. Hames, R. Ruiz, C. Scarlata, J. Sluiter, D. Templeton, et al., "Determination of structural carbohydrates and lignin in biomass," Laboratory analytical procedure, vol. 1617, pp. 1-16, 2008.

[22] I. O. Maile, E. Muzenda, and C. Mbohwa, "BiochemicalMethane Potential of OFMSW for City of Johannesburg," San Francisco on 26-28 October, 2016, 2016.

[23] O. I. Maile, E. Muzenda, and H. Tesfagiorgis, "chemical absorption of carbon dioxide in biogas purification," presented at the Procedia Manufacturing, 2017.

[24] J. Gao, L. Chen, Z. Yan, and L. Wang, "Effect of ionic liquid pretreatment on the composition, structure and biogas production of water hyacinth (Eichhornia crassipes)," Bioresource technology, vol. 132, pp. 361-364, 2013.

[25] F. Monnet, "An introduction to Anaerobic Digestion of Organic Wastes," 2003.

[26] P. Njogu, R. Kinyua, P. Muthoni, and Y. Nemoto, "Biogas production using water hyacinth (Eicchornia Crassipes) for electricity generation in Kenya," Energy and Power Engineering, vol. 7, p. 209, 2015. 